\title{
CONVERSACIÓN CON ELENA PONIATOWSKA, PREMIO CERVANTES 2013*
}

\author{
Fernando Galván \\ Universidad de Alcalá \\ Raquel Serur \\ Universidad Nacional Autónoma de México \\ Rosario Alonso Martín \\ Universidad de Salamanca \\ Sara Poot-Herrera \\ University of California, Santa Barbara \\ UC-Mexicanistas (Intercampus Research Program)
}

\begin{abstract}
Fernando Galván: Son innumerables los testimonios de reconocimiento que Elena Poniatowska ha recogido a lo largo de su amplísima trayectoria vital y literaria. En una entrevista que le hicieron para la revista 7 Días en el año 1971 le preguntaban sobre su ideología. Y la respuesta era: "Soy de origen polaco. ¿Cuál es la ideología de los polacos? Son gente que se lanzaba con caballos en contra de los tanques. Es una ideología un poco quijotesca, literaria, idealista, pero no es una ideología concreta ni activa...". Para nosotros en la Universidad es un gran privilegio que el nombre de Elena Poniatowska vaya ya unido indisolublemente al nombre de la Universidad de Alcalá y al nombre del Premio Cervantes, porque ella representa para nosotros muchos de los valores que aquí en la Universidad intentamos trasladar y compartir día a día con nuestros estudiantes y con los trabajadores, tanto dentro como fuera, de la institución. ;Cómo no recordar, por ejemplo, que ella fue

\footnotetext{
* Nota de la Redacción: El presente coloquio con Elena Poniatowska tuvo lugar el 24 de abril de 2014 en la Sala de Actos de la Universidad de Alcalá. Se celebró con motivo de la concesión a esta escritora del Premio Cervantes 2013 y estuvo conducido por el Rector de la Universidad de Alcalá, don Fernando Galván, y las especialistas Raquel Serur, Rosario Alonso Martín y Sara PootHerrera. Queremos agradecer a los trabajadores del Vicerrectorado de Extensión Universitaria de la Universidad de Alcalá -especialmente a Jesús Cañete y a Fernando Fernández Lanza- el habernos proporcionado la grabación del evento.

Por limitaciones de espacio, nos hemos visto obligadas a sintetizar las intervenciones de los diversos participantes. La edición es de Ana Rodríguez Callealta y Ana Casas.
} 
la ardiente defensora de los estudiantes y de la justicia cuando la cruel matanza de Tlatelolco en 1968! ¡Y cómo no recordar su defensa de los derechos civiles, de la educación, del respeto a los derechos humanos, sus denuncias contra los atropellos a que son sometidos los pobres y los indígenas en su país! ¡Cómo no reconocerle su lucha denodada por las mujeres, ignoradas, cuando no abiertamente despreciadas o perseguidas, en entornos machistas! Y no solo la defensa de artistas, muy conocidas en Europa, algunas menos pero muy representativas en México. Pienso en Frida Kahlo, en Pita Amor, en Nahui Olin, en María Izquierdo, en Elena Garro, Rosario Castellanos, Nellie Campobello, como hace en su libro Las siete cabritas, o en esa escalofriante y bellísima descripción de Leonora Carrington, en Leonora. Y también habría que recordar otras muchas mujeres, muchas anónimas, que aparecen en sus cuentos o en algunos otros libros, como Hasta no verte Jesús mío, Querido Diego, te abraza Quiela, Todo México, Paulina: las mil y una, De noche vienes, Tlapalería, Lilus Kikus. Si es difícil olvidarse de esos personajes grandiosos como Leonora, como Nellie Campobello, como Frida Kahlo, no lo es menos del personaje de la lavandera, de Josefina Bórquez o de Paulina. (Paulina es aquella niña de trece años que fue violada en Mexicali, a quien médicos y asociaciones religiosas le impedian abortar.) O de otros muchos personajes femeninos de ficción o trasunto muy claramente o muy directamente implicados en su propia vida (en La Flor de Lis, por ejemplo, es evidente que esos personajes de Mariana y Sofía, o los de sus padres Luz y Casimiro, provienen de la propia vida familiar de Elena). O las mujeres revolucionarias, sobre las que ha escrito tanto, por ejemplo en Las Soldaderas.

$Y$ tampoco puedo olvidarme del compromiso de Elena Poniatowska con las personas que sufren, con aquellas que tienen discapacidades físicas o mentales que les dificultan llevar una vida como las que llevan otros seres humanos. Estoy pensando en un libro como Gaby Brimmer, por ejemplo, que es un canto a la esperanza, un canto al heroísmo de la indígena Florencia que acompaña el progreso y el éxito de Gabriela Brimmer desde pequeña, y, por supuesto, de la propia Gabriela, ejemplo de superación de sus discapacidades.

Hay tantas vidas y tantas voces en la obra de Elena Poniatowska que es muy difícil resumir o hacer una síntesis de esa enorme diversidad.

Yo creo sinceramente que este es uno de los Premios Cervantes de más amplio espectro, pues Elena Poniatowska es una escritora que ha recorrido en su vida y en su escritura prácticamente todos los rincones y resquicios de la experiencia, desde, podríamos decir, las alturas del arte sublime hasta los abismos psicológicos más profundos, y pasando por las realidades más cotidianas, los acontecimientos más cercanos, desgarradores a veces, muy intensos. En esto, a mi juicio, Elena Poniatowska es absolutamente cervantina y quijotesca, no cabe discusión alguna. Es una escritora profundamente mexicana, es más que evidente cuando la oímos hablar, con ese lenguaje aprendido en la calle cuando llegó a México con apenas diez años de edad sin saber una palabra de español. Y a la vez, siendo una escritora profundamente mexicana, es una escritora universal, que apela a los grandes temas de la literatura de todos los tiempos y que revela, sin alardes ni presunciones, un amplísimo conocimiento y familiaridad con obras y autores de otras lenguas y otros territorios. 
Pero más allá de todo ello, como quizá habría dicho Carlos Fuentes si aún estuviera entre nosotros, Elena Poniatowska, "la Poni", como la llamaba él, es una escritora de La Mancha. No importa que haya nacido en Francia, que proceda de Polonia y que se enorgullezca de su mexicanidad. Su imaginación y su lenguaje, su cercanía y su diálogo con los lectores, en definitiva, su compromiso vital, son exactamente los mismos que los de Miguel de Cervantes y los del Quijote o, como nos decía ella ayer, en sus palabras, los de Sancho Panza, Elena Poniatowska-Sancho Panza. **

Raquel Serur: Si don Quijote transfigura la realidad del mundo y de las cosas, Elena Poniatowska, con una mirada quijotesca, consigna la realidad de un México al que nunca ha dejado de ver con asombro. A veces, mediante la técnica del zoom in, se mete en las minucias de un cotidiano acontecer en la vida de alguien que la toca, cuya vida es digna de ser relatada, como lo hace con Jesusa Palancares en Hasta no verte Jesús mío, y otras veces usa la técnica del zoom out para dar una crónica, una panorámica de múltiples voces, de una realidad que nos sobrepasa a todos los que la vivimos y que solo la pluma de Elena Poniatowska ha recogido con valor, como en La noche de Tlatelolco, por poner dos ejemplos relevantes. Detrás de las dos lentes está la mirada de Elena, quien tiene la necesidad de dar voz a aquellos que, por su pobreza, como Jesusa Palancares, o por razones políticas, como los estudiantes en 1968, son silenciados en México, y a quienes ella tiene la necesidad de rescatar, de devolverles la voz, aunque sea parcialmente, devolverles su dignidad y darles voz en su literatura.

Ahora, gracias al Premio Cervantes, quedan todos sus personajes, que mucho de quijotesco tienen, fijados con tinta indeleble en una vasta obra literaria que da cuenta del México que muchos quisieran olvidar. Ella se llamó a sí misma ayer, en el discurso de entrega, Sancha Panza, y es cierto. Elena, para mí, tiene una doble virtud: la de un Sancho que sabe qué es un molino de viento y qué un gigante, y la de un Quijote, que ingenua y osadamente, con su pluma en la mano, supo mostrar a nuestra generación y a las que le siguieron que hay cosas sobre las que el silencio no es una opción válida. Elena Poniatowska rompió con una autocensura impuesta por los gobiernos prístas, aquellos a quienes Vargas Llosa calificó como "una dictadura perfecta" y quienes reprimieron a los estudiantes en 1968, fecha en la que México atestiguó cómo le mataron a una buena parte de su juventud pensante, a una buena parte de mi generación. Elena como un Quijote, salió en busca de una atroz verdad, aquella que escrupulosamente había ocultado la prensa cuando el hecho estaba perpetrado, como dice Shakespeare: "The deed is done". La noche de Tlaltelolco es una polifonía de voces con un único reclamo: dignidad y justicia. El gobierno se dio cuenta de que ese libro era una bomba que caía en las entrañas de su estructura y trató de retirarlo pero no pudo. Luego se dio el lujo de intentar premiarlo para congraciarse con Elena, seguramente con el plan mañoso de creerla

\footnotetext{
** Nota de la Redacción: Alusión al discurso pronunciado por Elena Poniatowska en el Paraninfo de la Universidad de Alcalá el día 23 de abril de 2014 con motivo de la recepción del Premio Cervantes 2013. Puede leerse en <http://www2.uah.es/diariodigital/images/04curso20132014/ PDFs/discurso_poniatowska.pdf >.
} 
sobornable. Poniatowska no solo no aceptó el prestigioso premio Villaurrutia, sino que les contestó: "Y ¿quién va a premiar a los muertos?"

Se hace camino al andar, golpe a golpe, verso a verso, dijo el poeta. Lo supo Cervantes con su Quijote, lo sabe nuestra Quijota sanchopancesca o la Sancha-quijotesca Elena Poniatowska, la princesa roja, como le suelen decir. En un nuevo rincón de La Mancha, en el barrio de Chimalistac en la Ciudad de México, Elena escribe, no se cansa nunca. Hasta ahora, entre narrativa, poesía, ensayos, biografías noveladas, crónicas, entrevistas y otros géneros, ha producido cuarenta y siete libros por los que ha merecido muchos premios, distinciones y once doctorados Honoris Causa.

Por lo mismo, por el privilegio de tenerte aquí, te pregunto, Elena, porque sé que no paras nunca de trabajar y que tienes varios proyectos en puerta, ¿en qué estás trabajando ahora? y ¿por qué te interesan esos proyectos?

Elena Poniatowska: Estoy trabajando en una novela sobre los Poniatowski, porque, cuando vine a México a los diez años, ya no supe casi nada de ellos y, de repente, al leer la biografía de Catalina la Grande, que fue una emperatriz de todas las Rusias, me surgió la idea. De veras las feministas deberían de entronizarla porque tuvo muchísimos amantes, casi hasta el momento de su muerte, y además porque fue una mujer que se levantaba a las cinco de la mañana, prendía ella misma la calefacción, se preparaba un té y leía a Voltaire, a Diderot... Ella empezó a hacer de Moscú, y sobre todo de San Petersburgo, una ciudad de la cultura. Entre los personajes que la visitaban, estaba Estanislao Poniatowski -no fue su primer amante, fue el segundo-, que se enamoró perdidamente de ella. Me dije que este personaje tan enamorado era bastante simpático. Antes no le había encontrado sus cualidades, pero después descubrí que había traído a italianos cuando fue un rey en una época muy difícil. Mientras Varsovia era casi un llano, construyó palacios, trajo a dos importantes pintores de Italia -Canaletto y Guardi-, una pintora francesa -Vigée-Lebrun-, que era también una gran pintora, y además fue un rey magnánimo, un rey simpático, un rey buena persona, amigo de Casanova, porque le gustaban muchísimo las mujeres, que para mí es una cualidad... Y entonces a raíz de él me dije: "voy a hacer esta novela". Empecé a escribir y me di cuenta de que lo que estaba haciendo es lo que llamamos en México "fusilar" las biografías de Catalina la Grande, y necesitaba saber más de Poniatowski. No sé polaco, así que recurrí al archivo de la familia y me encontré una carta de amor muy bella que dice: "Yo no quiero ser rey, yo quiero estar en tu lecho". Pero Catalina nunca lo volvió a tomar como amante porque la emperatriz relevaba a sus amantes como cataplasmas, uno tras otro.

Y luego tengo otra novela que está más adelantada sobre una esposa de Diego Rivera, posterior a Angelina Beloff, con quien tuvo su primer hijo que murió de meningitis y de frío en París. Se trata de Lupe Marín, con la que Rivera tuvo dos hijas y que era una fiera, una especie de pantera con ojos de sulfato de cobre -verde-grises-, que se dan en pocas ocasiones en las mujeres muy hermosas. Una mujer, en efecto, muy hermosa, pero que finalmente he descubierto que era mala, y eso me llama mucho la atención: no era una buena mamá, no se 
ocupó mucho de sus hijas... Pero es un gran, gran personaje. Sobre todo, a través de ella puedo revivir toda una época de un México que ya no hemos vuelto a conocer, porque yo considero que ahora nuestro México es inferior a su pasado en lo que a arte se refiere.

RAQUel SeRUR: Te he oído hablar de otro proyecto sobre un personaje español...

Elena Poniatowska: Aquí me llamó la atención la duquesa de Medina Sidonia, porque creo que era muy bárbara. Para eso tendría que entrevistar a sus hijos, si es que los tiene. Me parece un personaje que se sale de lo común, aunque no sé nada de ella, ni siquiera si era guapa, alta, flaca, gorda..., nada. Solamente conozco su historia, que leí en Internet.

Raquel Serur: Elena, tú que has hecho entrevistas magníficas, con las que nos has descubierto amplios horizontes, me pregunto si nunca has tenido la fantasía de hacer entrevistas imaginarias, de entrevistar a escritores que no han sido tus contemporáneos. A Cervantes, por ejemplo, ¿qué se te habría ocurrido preguntarle?

Elena Poniatowska: Te puedo decir que en el convento de monjas donde me eduqué, por razones de religión y porque nos la vivíamos en la capilla, me la pasaba entrevistando a Juana de Arco. No sé por qué tenía una fijación en Juana de Arco, y lo que más me fascinaba de ella es que el Delfín de Francia -le Dauphin- se había escondido para que ella no pudiera reconocerlo. Le presentaron a otro que no era, pero ella dijo: "No, tú no eres, el Delfín está allá", y fue derechito a buscarlo. Eso me impresionaba mucho más, quizá por el instinto periodístico, que el hecho de que fuera quemada en la leña. También me impresionaron otros personajes, como las tricoteuses que tejían mientras caía la guillotina encima de los aristócratas, los compañeros de Luis XVI y Luis XIV.

Rosario Alonso Martín: Hablar brevemente de la obra de Elena y de la vida de Elena, es como diría Sor Juana Inés de la Cruz, una presunción vana. Es completamente imposible que en una hora, hora y media de conversación ofrezcamos una idea totalizadora del trabajo ingente, infinito, de Elena Poniatowska. A este respecto, me ha emocionado mucho leer unas declaraciones de Paula Haro, su hija, en las que dice: "yo siempre he recordado a mi madre trabajando" y "a mí lo que me relaja es el sonido de una máquina de escribir", porque esa es la música que acompaña a Elena Poniatowska.

Pero sobre todo hay que leerla: un libro, otro libro, otro libro, con esa voluntad de hierro que ella tiene de mostrar lo que al poder no le gusta que se muestre. Verdaderamente si leemos el magnífico discurso que ayer nos entregó veremos que este es una bomba de relojería. Yo me preguntaba: “iverdaderamente las autoridades se dan cuenta de lo que están oyendo?". Han premiado a los que nunca ni tienen ni han tenido ni van a tener más que la esperanza y el trabajo de quienes son activistas, pero no activistas de relumbrón, sino diarios y constantes. $Y$ como tengo que hacer una pregunta directa, y ya que estamos en una charla y con 
gente joven, y ella nunca se niega a ir una charla, un coloquio, una conferencia, un encuentro, quisiera preguntarle: ¿qué te aporta a ti el contacto, el congreso con el académico, con los estudiantes?

Elena Poniatowska: Creo que sin esta aportación, sin este intercambio, simplemente no podría seguir adelante, porque es la comprobación de que sí se lee, sobre todo en México. Un país donde hay mucho analfabetismo y donde los periódicos, que son muchos, no tienen grandes tirajes. Todas esas revistas, esos periódicos, son un negocio más para defender los intereses del dueño, que se dice, por ejemplo: "yo soy un distribuidor de automóviles -como sucedía con el Novedades- y me conviene defender la concesión de la línea blanca de las carreteras", de modo que hay ciertos temas, como las carreteras, que no se pueden tocar. A veces el periódico ni siquiera es un negocio, pero sí defiende los negocios del empresario en turno o del poderoso en turno. Por eso, me alimenta ver a la gente, salir a las conferencias; es un nutriente, son unas vitaminas súper poderosas, que me alientan al día siguiente a levantarme con muchas ganas solo porque una señora se acercó, o porque ha sido tan importante para mí lo que me dijo alguien a quien le gustó lo que yo escribía. Ese intercambio es algo que necesito como un alimento para poder seguir adelante.

Sara Poot-Herrera: Se cumplen ahora sesenta años de la publicación de Lilus Kikus (1954) pero, a pesar del tiempo transcurrido, de Elena Poniatowska puede decirse lo mismo que Carlos Monsiváis decía de Margo Glantz: cuando sube hacia una pirámide, cuando sube a las alturas, va tirando los años. Y Elena Poniatowska cuando habla va también tirando los años. Las palabras le dan vida, responden como espejo a la vida que ella les da. Elena y palabra se hacen jóvenes, son jóvenes, se pulen recíprocamente, cuidan el cuerpo y el alma de la otra. Cuando Elena calla y cuando habla es curiosa y le quita el prefijo al curioso impertinente. Y tampoco pone en riesgo sus afectos porque los cuida mucho. El Amor de su apellido materno está en sus letras y su gente, en todo México.

En 2012 hablamos de su fama y la relacionamos en la revista Proceso con la fama de Sor Juana. Sor Juana conquistó España con su obra; Elena conquista ahora España y la ha venido conquistando con sus libros. La escritora novohispana y la escritora mexicana nos llevan a ese momento, a esa primera fama, a ese primer sueño de Sor Juana y a su mundo iluminado, al universo de Elena, a su libro sobre el estrellero y su piel del cielo. Las dos son neptunas, constelaciones en esa memoria que ha hecho de México (en esa memoria extendida, en esa metáfora) una especie de alegoría. Sin Elena en el siglo xx y en estos años del xxı la literatura mexicana no sería lo que es, como la literatura novohispana no lo sería sin nuestra Décima Musa.

A mí me gustan mucho estas dos escritoras que son así como "láminas las estrellas compongan", y, en este caso, "las estrellas" no es el hipérbaton de Sor Juana, sino que son ellas las que componen esas láminas, las láminas de la escritura. Me gusta mucho el sentido del humor de cada una, su genio e ingenio, me gustan mucho las manos de su oficio: las manos de los personajes de Elena, las manos de 
las lavanderas, del obrero, las manos del campesino, de la fotógrafa, del pintor, las manos por siempre jóvenes. Elena es como una especie de estética de la sencillez y, al mismo tiempo, es una especie de teoría adelantada. Nadie hablaba de polifonía cuando publicó su libro en el 68. Entonces nadie hablaba de cruce de géneros o, como dicen ahora, de hibridez.

Allá viene una primera pregunta: cuando cambió el milenio, en El país se publicó una lista de "obras perfectas", en la que aparecía Querido diego, te abraza Quiela. Elena, ¿qué sentiste cuando supiste que entre tus novelas, Querido Diego, te abraza Quiela se consideraba una novela perfecta?

Elena Poniatowska: Para mí es un gusto enorme que me digas eso, pero, cuando escribí este libro, yo sentí que eran unas cartas de amor que en el fondo están un poco escritas a Guillermo Haro, aunque también están ligadas a las otras cartas de amor que se han escrito en el tiempo. A mí me han dicho que es un libro muy triste, que se parece un poco a lo que haría Rosario Castellanos, que, según decían algunos, siempre se estaba lamentando de algo. Lo que tú me dices de que es una novela perfecta me da una inmensa alegría, porque es una sorpresa, es una novedad. Yo creo que es una historia de amor un poco sin respuesta, pero así son las historias de amor de muchísimas mujeres. Se lanzan como yeguas desbocadas a amar a alguien que finalmente o sale corriendo o las rechaza.

La anécdota que hizo que escribiera esta novela es que Diego Rivera, que tuvo un hijo con Angelina Beloff en París, nunca le envió el dinero para que lo alcanzara. Eran muy pobres para que Angelina hiciera el viaje, pero finalmente ella reunió el dinero. Fue al Palacio de Bellas Artes, donde había un gran pasillo con una alfombra roja con butacas a los lados. Se puso en la butaca de la orilla para que, cuando él pasara, la viera, pero la anécdota es que él pasó y ni siquiera la reconoció. Rivera ya estaba casado con Lupe Marín, tenía hijos con ella, y ni siquiera reconoció a Angelina. A mí esto me provocó una enorme tristeza y empecé a escribir las cartas que yo creía que Angelina Beloff le habría escrito a Diego Rivera. Encontré unas primeras cartas, una o dos, en el libro de Bertram Wolfe titulado The fabulous life of Diego Rivera (está traducido al español como La vida fabulosa de Diego Rivera), donde también hay unos cuantos capítulos dedicados a esta mujer, que era una rusa blanca que le ayudó muchísimo cuando vivió en París.

Sara Poot-Herrera: Aquí podemos marcar una nueva semejanza: en el caso de los sonetos de Sor Juana, se juega con la idea del amor: "con quién me quedo: con quien me quiere y yo no quiero, o con quien yo quiero y a mí no me quiere". Sor Juana, que no es platónica, decide: "me enamoro y me vuelvo a enamorar", por lo que en el soneto se decanta por la salud: "me quedo con quien me quiere". En el caso de Elena, sus personajes están muchas veces solos, de allí que la frase de Jesusa Palancares, y de Elena Poniatowska, rece: "las reinas siempre van solas". Estas mujeres solas, como diría Ana Bundgaard, poeta gallega que vive en Dinamarca, "quedan solas, pero en su soledad crean". Es el acto de la creación, de la pintura en el caso de Angelina Beloff, también de Leonora Carrington, de la fotografía en el caso de Graciela Iturbide, entre otras artistas. ¡Y qué decir de Sor Juana! 
Muy brevemente decíamos hace un rato que la obra de Elena Poniatowska está llena de afectos, y los suyos son superlativos. A veces no gustan los esdrújulos en la literatura, pero me encanta pensar en Elenísima, en famosísima, mexicanísima, minúscula, mayúscula, escritora de La Mancha, escritora sin mancha, y nos preguntamos: "la princesa está alegre, ¿qué tendrá la princesa?"; pues ahora nada menos que el Cervantes. O "Elenita está alegre la facultad. ¡Ay Elena tan Poniatowska como Amor". ¿Qué haces tú con tanto amor que te tenemos, Elena? Aparte de tus libros, que nos hacen sentir que son nuestros.

Elena Poniatowska: Bueno, primero te quería decir algo a propósito de la soledad que dices que tenemos que asumir las escritoras. Siempre pienso que san Agustín dijo que para crear era muy importante hacer el amor muy poquito o no tener grandes relaciones amorosas, lo cual fue muy benéfico para Sor Juana, puesto que fue una extraordinaria creadora. Y con relación a mí, se lo dejo como una pegunta en el aire.

En cuanto lo que significa para mí estar aquí, y atreverte, porque es un atrevimiento tuyo, de compararme con Sor Juana, porque Sor Juana es la máxima figura, yo creo no solo de México, sino de todo el continente... Octavio Paz alguna vez declaró que el mayor poeta del continente de habla hispana era Sor Juana Inés de la Cruz. Te imaginas entonces que no puedo ni siquiera acercarme. Claro que me conmueve mucho que tú lo hagas, porque tú eres una sorjuanista que has escrito muchos ensayos sobre ella.

Sí quisiera agradecer el apoyo que me han dado, Charo aquí en España, Raquel en la Universidad en México -antes estuvo en El Colegio de México-y Sara, también de El Colegio de México y ahora en la Universidad de Santa Barbara con esa extraordinaria fundación que se llama UC-Mexicanistas. Son los que estudian México en las universidades norteamericanas, una asociación cada vez más grande que también reúne a investigadores europeos, y que divulga la cultura mexicana a muy alto nivel, como, por desgracia, no han logrado hacer los embajadores de México en los países a los que están invitados.

Sara Poot-Herrera: Agradezco la mención a UC-Mexicanistas, orgullosos de que Elena Poniatowska esté entre sus integrantes. Es ella quien pone en alto el español mexicano, da rienda suelta a la palabra oral, testimonia hechos, ficcionaliza situaciones, musicaliza la poesía, y es ojo, oído, olfato, textura de su tiempo, sus sabores y sinsabores. Un día el ideal se acopló con la realidad en la persona de una mujer que sonriente en la Universidad de Alcalá recibe el Premio Cervantes y se lo coloca en el pecho luminoso desde donde el cupido de sus letras enamora a los lectores con la flecha certera de los signos de su corazón. 